in the treatment group had lower pain scores, reduced opioid consumption and no long-term complications.

At the Vancouver Hospital we have used intercostal cryoneurolysis in over 1500 thoracotomy patients. Since 1988 we have reduced the duration of each cryosession to $30 \mathrm{sec}$ and our thoracic surgeons report that the incidence of numbness or dysaethesia lasting more than two months is virtually zero. Cryoanalgesia remains an important component in the management of thoracotomy pain at our hospital, as at other centres. ${ }^{6}$

Raymer P. Grant MD FRCPC

Head, Division of Thoracic Anaesthesia

Vancouver Hospital and Health Sciences Centre

(12th and Oak Pavilions)

REFERENCES

1 Johannesen N, Madsen G, Ahlburg P. Neurological sequelae after cryoanalgesia for thoracotomy pain relief. Ann Chir Gynaecol 1990; 79: 108-9.

2 Muller LC, Salzer GM, Ransmayr G, Neiss A. Intraoperative cryoanalgesia for postthoracotomy pain relief. Ann Thorac Surg 1989; 48: 15-8.

3 Roxburgh JC, Markland CG, Ross BA, Kerr WF. Role of cryoanalgesia in the control of pain after thoracotomy. Thorax 1987; 42: 292-5.

4 Maiwand MO, Makey $A R$, Rees $A$. Cryoanalgesia after thoracotomy. Improvement of technique and review of 600 cases. J Thorac Candiovasc Surg 1986; 92: 291-5.

5 Roberts D, Pizzarelli G, Lepore V, al-Khaja N, Belboul A, Dernevik $L$. Reduction of post-thoracotomy pain by cryotherapy of intercostal nerves. Scand J Thor Cardiovasc Surg 1988; 22: 127-30.

$6 \mathrm{Katz} J$. Cryoanalgesia for postthoracotomy pain (Editorial). Ann Thorac Surg 1989; 48: 5.

\section{Posterior lumbar plexus block}

To the Editor:

I wish to congratulate Farny et al. on their work on the posterior lumbar plexus block. ${ }^{1,2}$ They have described in detail the relevant anatomy of the lumbar plexus. ${ }^{\prime}$ They have quite convincingly demonstrated that there is no "psoas compartment" into which local anaesthetic can be deposited other than the psoas muscle itself. This observation has important implications. For example, there is a great deal of evidence to suggest that local anaesthetic does not travel proximally to the lumbar plexus by a common fascial compartment following a femoral 3-in1 nerve block ${ }^{3}$ as suggested by Winnie. ${ }^{4}$ This is because such a compartment does not exist as demonstrated by Farny et al. ${ }^{1}$ and Ritter. ${ }^{5}$

In clinical study by Farny $e t a l .{ }^{2}$ there are some methodologic flaws and their conclusions may be unfounded. They stated that the purpose of the study was "to define the clinical potential of posterior lumbar plexus blockade when combined with a sciatic nerve block" and "that the combination of these two blocks is necessary to provide anaesthesia to the entire lower extremity." Successful blocks were defined as the ability to perform surgical procedures on the lower extremity (principally ankle surgery or knee arthroscopy) without conversion to general anaesthesia. This would have been an acceptable endpoint if the surgical procedures involved had required anaesthesia in all of the nerves to the lower extremity. However, 33 of 45 patients underwent knee arthroscopy with or without meniscectomy and these surgical procedures do not require sensory anaesthesia of both the sciatic nerve and the lumbar plexus. They are commonly performed with only intra-articular local anaesthetic and intravenous sedation and analgesia. ${ }^{6}$ Twenty-two of 45 patients had surgical procedures below the knee and sciatic nerve block with or without a saphenous nerve block may be all that is necessary.

The authors advocate this technique for outpatient surgery. They state that surgery started $35 \pm 24 \mathrm{~min}$ after the end of the second block. The time to completion of the blocks averaged $8 \pm 5.9 \mathrm{~min}$ (range 3-40 min). The patients left the hospital $337 \pm 49$ min after the blocks. In our institution arthroscopic meniscectomy takes 20 to $30 \mathrm{~min}$ to perform and patients go home within one to two hours of the surgery which is performed with intra-articular local anaesthetic.

\section{S. Lang MD FRCPC \\ Department of Anaesthesia \\ University of Saskatchewan \\ Royal University Hospital \\ 103 Hospital Drive \\ Saskatoon, Saskatchewan, Canada S7N 0W8}

\section{REFERENCES}

1 Farny J, Drolet P, Girard M. Anatomy of the posterior approach to the lumbar plexus block. Can J Anaesth 1994; 41: 480-5.

2 Farny J, Girard M, Drolet P. Posterior approach to the lumbar plexus combined with a sciatic nerve block using lidocaine. Can J Anaesth 1994; 41: 486-91.

3 Lang SA, Yip RW, Chang PC, Gerard MA. The femoral 3-in-1 block revisited. J Clin Anesth 1993; 5: 292-6.

4 Winnie AP, Ramamurthy $S$, Durrani $Z$. The inguinal paravascular technique for lumbar plexus anesthesia: the "3in-1" block. Anesth Analg 1973; 52: 989-96.

5 Ritter J, Zimpfer $M$. Femoral nerve sheath for lumbar plexus block is not found in cadavers. Anesthesiology 1993; 79: A821.

6 Ardahl M, Dasta J, Zuelzer W, McSweeney T. Lidocaine local anesthesia for arthroscopic knee surgery. Anesth Analg 1990; 71: 670-4. 